\title{
The Effect of Casein Phosphopeptide-Amorphous Calcium Phosphate on the Microhardness of Carbamide Peroxide Bleached Enamel (An in Vitro Study)
}

\author{
Hagar M. Ali ${ }^{1}$, Ibrahim L. El-gayar ${ }^{2}$, Wegdan M. M. Abdel-Fattah ${ }^{3}$, Mona M. Ghoneim ${ }^{4}$ \\ ${ }^{1}$ Master student of Operative Dentistry, Department of Conservative Dentistry, Faculty of Dentistry, Alexandria University, Egypt \\ ${ }^{2}$ Professor of Operative Dentistry, Department of Conservative Dentistry, Faculty of Dentistry, Alexandria University, Egypt \\ ${ }^{3}$ Professor of Operative Dentistry, Department of Conservative Dentistry, Faculty of Dentistry, Alexandria University, Egypt
}

${ }^{4}$ Assistant professor of Operative Dentistry, Department of Conservative Dentistry, Faculty of Dentistry, Alexandria University, Egypt

\begin{abstract}
Objectives: This in vitro study is designed to evaluate the effect of casein phosphopeptide-amorphous calcium phosphate $(C P P-A C P)$ on microhardness and surface morphology of bleached enamel surface using $10 \%$ and $15 \%$ carbamide peroxide bleaching gel. Methods: This study will involve a total of 40 premolars which will be divided into four groups (n=10) according to the bleaching agent used: $10 \%$ carbamide peroxide only, $10 \%$ carbamide peroxide with CPP-ACP paste, $15 \%$ carbamide peroxide only and $15 \%$ carbamide peroxide with CPP-ACP paste. During the 14-day bleaching regimen, the samples will be stored in artificial saliva. The Vickers microhardness will be assessed at baseline (T0) and immediately after the bleaching regimen (T14) using a microhardness tester. Scanning electron microscopy will be used to study the morphology of enamel with and without CPP-ACP. Results: There was a significant increase in microhardness of enamel in group used CPP-ACP with carbamide peroxide (10\% and 15\%) and surface morphology was improved by using the remineralizing agents. Data will be analyzed statistically using ANOVA and Post hoc test. Conclusions: The use of CPP-ACP paste with $10 \%$ and $15 \%$ carbamide peroxide increased post bleaching enamel microhardness and was effective on repairing enamel surface morphology.
\end{abstract}

Keywords: Enamel bleaching, Remineralization, Microhardness, Surface morphology

\section{Introduction}

The search for a more esthetic smile has grown exponentially during the last few decades, so that tooth color is currently believed to be one of the biggest concerns for patients [1]. With careful diagnosis and appropriate attention to technique, bleaching may represent a more conservative and safer means to lightening discolored teeth [2].

Although at-home bleaching is an effective technique for whitening discolored teeth, whether carbamide peroxide- or peroxide-containing agents can soften dental hard tissues is still being debated [3]. Concerning the effects of whitening products on mineral loss in dental hard tissues, studies that investigate external bleaching therapies often test for microhardness because this is related to the mineral content of the tooth [4]. Moreover, it has also been postulated that although a decrease in the microhardness of bleached enamel might occur, it can be reversed after a postbleaching period of remineralization through the absorption and precipitation of salivary components, such as calcium and phosphate [5]. The benefit of using remineralizing agents in bleaching peroxides could include a reduction in enamel solubility and reduced sensitivity due to mineral deposition in enamel crystallites [6].

Remineralization is a simple chemical process which requires no growth factor and soft-tissue biological process in order to take effect [7]. In other words, remineralization is defined as the process whereby calcium and phosphate ions are supplied from an external source to the tooth to promote ion deposition into crystal voids in demineralized enamel to produce net mineral gain [8]

The possibility of remineralizing bleached enamel has been investigated, however, the results are conflicting. The addition of fluoride and calcium in the bleaching agent did not result in higher means of enamel microhardness [9]. In a study by Burgmaier and others, the authors did not observe any improvement in fluoride uptake in bleached enamel [10].

The association of a CPP-ACP paste (Tooth Mousse, GC Corporation, Tokyo, Japan) with carbamide peroxide has been studied [11], and the study's authors suggest that Tooth Mousse can be applied concurrently with the bleach and would not reduce bleaching effectiveness. The present study aims to evaluate a CPP-ACP paste (MI Paste, GC, Tokyo, Japan - an analogue to Tooth Mousse) mixed with $10 \%$ and $15 \%$ carbamide peroxide on enamel microhardness and enamel surface morphology.

Various studies have used different methods to assess the process of enamel remineralization. The commonly used microhardness tests for evaluating enamel remineralization are Vickers microhardness test [12]. In this study we will focus on evaluation of surface microhardness of enamel, thus Vickers surface microhardness test will be used and surface morphology of enamel using scanning electron microscopy (SEM). 


\section{Materials and Methods}

1) Materials:

a) Bleaching gel

- $10 \%$ carpamide peroxide bleaching agent: Opalescence 10\% (Ultradent Products, inc, South Jordan, UT, USA.).

- $15 \%$ carpamide peroxide bleaching agent: Opalescence $15 \%$ (Ultradent Products, inc, South Jordan, UT, USA.).

b) Remineralizing agent $\mathrm{CPP}$ - ACP

- Casein Phosphopeptide - Amorphous Calcium Phosphate: GC Tooth Mousse (GC Corp., Tokyo, Japan).

\section{2) Equipments}

- Vickers microhardness tester (Wolpert Wilson instrumentsTM, USA).

- Scanning electron microscope (SEM) (JOEL JSM 5300 Scanning Microscope, Japan)

\section{3) Methods}

\section{a) Teeth Selection}

Forty extracted human premolars, extracted for periodontal reasons or orthodontic reasons, were selected for this study. The teeth were collected from oral surgery department of the Faculty of Dentistry, Alexandria University and from hospitals of Ministry of Health. Teeth with cracks, caries, intrinsic stains or restorations were excluded. Calculus and stains were removed with hand scaler, rubber cup \& polishing paste. The teeth were debrided and stored in normal saline at room temperature from the day of extraction until the test was done.

\section{b) Specimens' Preparation}

The roots were removed $2 \mathrm{~mm}$ apically to the cementoenamel junction using double-faced diamond disks (KG Sorensen, Barueri, Brazil) and were discarded. The teeth were positioned in a mold and embedded using a selfcuring polystyrene resin (Piraglass, Piracicaba, SP, Brazil). The enamel surfaces of the teeth were ground flat using SiC paper (80-grit) and polished using 600-, 1200-, and 2400-grit aluminum oxide abrasive papers and a $0.4-1 \mathrm{~m}$ alumina polishing suspension on a polishing machine (APL-4, Arotec, Sao Paulo, SP, Brazil), exposing enamel in a circular area $10 \mathrm{~mm}$ in diameter.

\section{c) Baseline Microhardness Assessment (T0)}

The enamel microhardness determination was performed with a microhardness tester (Wolpertwilson instruments ${ }^{\mathrm{TM}}$, USA) fitted with a $100 \mathrm{~g}$ load, which was used to make indentations on the enamel surface. The loaded diamond was allowed to sink and rest on the enamel surface for 10 seconds and the Vickers hardness number was thus determined. Three indentations were performed on each specimen, with a distance of $100 \mathrm{~lm}$ between them, and then they were averaged [13].

\section{d) Grouping}

The samples were randomly divided into 4 groups of 10 samples in each:

Group I: Bleaching with $10 \%$ carbamide peroxide only.
Group II: Bleaching with $10 \%$ carbamide peroxide and CPPACP paste.

Group III: Bleaching with $15 \%$ carbamide peroxide only. Group IV: Bleaching with $15 \%$ carbamide peroxide and CPP-ACP paste.

\section{e) Bleaching Procedures}

The bleaching treatment was performed over 14 days, according to the manufacturer's instructions. For each specimen

For groups 2 and 4, the peroxides were mixed with MI Paste (GC Corporation). The mixtures were freshly prepared by mixing bleaching gel with MI Paste until a homogeneous paste was obtained, which was then inserted into a 5-mL syringe. In addition, the peroxides alone were put into 5-mL syringes. The contents of each syringe were used to bleach the teeth for seven days, and then the mixtures were prepared again [13].

Every day, the bleaching agents were placed on the enamel. Each specimen was then positioned for eight hours at room temperature in artificial saliva. After eight hours, the gel was removed from the enamel surface by placing it under running distilled water for 15 seconds. When the specimens were not in contact with the bleaching agents, they were immersed in artificial saliva kept at room temperature, which was changed daily [13]

\section{f) Final Microhardness Assessment}

Immediately after bleaching (T14), another Vickers microhardness measurement was taken in the samples following experimental conditions similar to those used at baseline.

\section{g) Scanning Electron Microscopy}

3 specimens from each group were observed by Scanning Electron Microscopy.

\section{h) SEM Observations}

The specimens were gently air dried, dehydrated with alcohol and then dried at the critical point - a method used to minimize specimen distortion due to drying tensions. The samples were mounted on a stub of metal with adhesive, sputter-coated with 40-60 nm of gold and then analyzed under scanning electron microscopy (440 SEM with Oxford EDS/ WDS, LEO.).

Serial SEM microphotographs of the surfaces of each specimen at 5,000X and 10,000X original magnification were obtained. The superficial morphology of enamel was examined (14).

\section{i) Statistical analysis of the data (15)}

Data were fed to the computer and analyzed using IBM SPSS software package version 20.0 (16). Quantitative data were described using range (minimum and maximum), mean and standard deviation. Significance of the obtained results was judged at the $5 \%$ level.

The used tests were:

ANOVA with repeated measures for normally quantitative variables, to compare between more than two periods or stages, 


\section{International Journal of Science and Research (IJSR) \\ ISSN (Online): 2319-7064 \\ Index Copernicus Value (2013): 6.14 | Impact Factor (2015): 6.391}

and Post Hoc test (Bonferroni adjusted) for pairwise comparisons.

\section{Results}

The results of the current study were analyzed statistically and histologically.

\section{Microhardness Data}

he mean Vickers Hardness Number (VHN) and standard deviation results for enamel microhardness of group I and II are presented in (Table 1, Figure 1). Table 1 showed enamel microhardness values of group bleached with $10 \%$ carbamide peroxide only at baseline and after 14 days of bleaching $(336.70 \pm 14.87)$ and $(305.20 \pm 8.92)$ respectively and there was statistically significant difference $(\mathrm{P}$ value $<0.001)$. While results of group bleached with $10 \%$ carbamide proxide and CPP-ACP showed enamel microhardness value at baseline and after 14 days of bleaching $(336.70 \pm 14.87)$ and $(333.20 \pm 12.66)$ respectively with no statistically significant difference ( $\mathrm{P}$ value 1.000).

Table 1: Mean and standard deviations of the Vickers Hardness Number of $10 \%$ carbamide peroxide with and without CPP-ACP

\begin{tabular}{|c|c|c|c|}
\hline & T0 & T14 10\% & $\begin{array}{c}\text { T14 } \\
\mathbf{1 0 \%}+\text { CPP }\end{array}$ \\
\hline Min. - Max. & $309.0-354.0$ & $289.0-322.0$ & $312.0-352.0$ \\
\hline Mean \pm SD. & $336.70 \pm 14.87$ & $305.20 \pm 8.92$ & $333.20 \pm 12.66$ \\
\hline $\mathbf{p}_{\text {T0 }}$ & & $<0.001^{*}$ & 1.000 \\
\hline
\end{tabular}

$\mathbf{p}_{\mathbf{T} 0}$ : $\mathrm{p}$ value for Post Hoc test (Bonferroni adjusted) for comparison between T0 and T14 10\% carbamide peroxide and T14 10\% carbamide peroxide + CPP

$*$ : Statistically significant at $\mathrm{p} \leq 0.05$

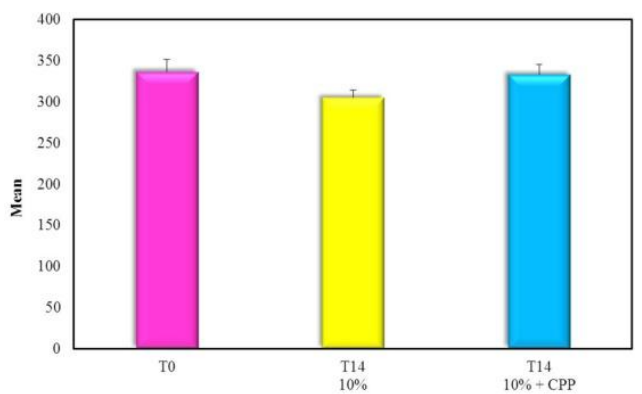

Figure 1: Mean and standard deviations of the Vickers Hardness Number of $10 \%$ carbamiole peroxiole and $10 \%$ carbamiole peroxiole + CPP.ACP

The mean Vickers Hardness Number (VHN) and standard deviation results for enamel microhardness of group III and IV are presented in (Table 2, Figure 2). Table 2 showed enamel microhardness values of group bleached with $15 \%$ carbamide peroxide only at baseline and after 14 days of bleaching $(336.70 \pm 14.87)$ and $(296.70 \pm 8.94)$ respectively and there was statistically significant difference ( $\mathrm{P}$ value $<0.001)$. While results of group bleached with $10 \%$ carbamide proxide and CPP-ACP showed enamel microhardness value at baseline and after 14 days of bleaching $(336.70 \pm 14.87)$ and $(324.50 \pm$ $7.79)$ respectively with no statistically significant difference $(P$ value 0.167 ).
Table 2: Mean and standard deviations of the Vickers Hardness Number of $10 \%$ carbamide peroxide with and without CPP-ACP

\begin{tabular}{|c|c|c|c|}
\hline & T0 & $\begin{array}{c}\text { T14 } \\
\mathbf{1 5 \%}\end{array}$ & $\begin{array}{c}\text { T14 } \\
\mathbf{1 5 \%}+\text { CPP }\end{array}$ \\
\hline Min. - Max. & $309.0-354.0$ & $281.0-309.0$ & $317.0-352.0$ \\
\hline Mean \pm SD. & $336.70 \pm 14.87$ & $296.70 \pm 8.94$ & $324.50 \pm 7.79$ \\
\hline p $_{\text {T0 }}$ & & $<0.001^{*}$ & 0.167 \\
\hline
\end{tabular}

$\mathbf{p}_{\mathrm{T} \mathbf{0}}: \mathrm{p}$ value for Post Hoc test (Bonferroni adjusted) for comparison between $\mathrm{T} 0$ and $\mathrm{T} 1410 \%$ carbamide peroxide and T14 10\% carbamide peroxide + CPP

$*$ : Statistically significant at $\mathrm{p} \leq 0.05$

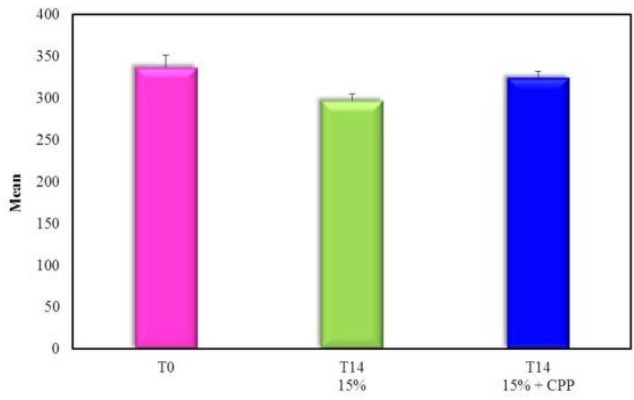

Figure 2: Mean and standard deviations of the Vickers Hardness Number of $15 \%$ carbamiole peroxiole and $15 \%$ carbamiole peroxiole + CPP.ACP.

Scanning electron microscope images evaluation

\section{- SEM micrograph of the sound enamel surface}

Specimens stored in artificial saliva. Remarkable morphologic alterations were not detected on unbleached enamel surfaces. The surface was not completely smooth; however the aprismatic surface layer was uniform. (Figure 3)

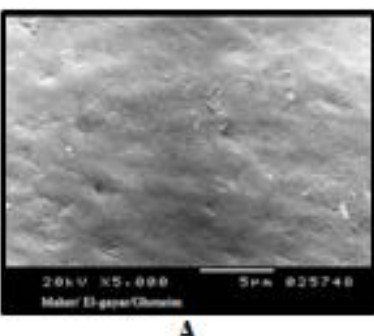

A

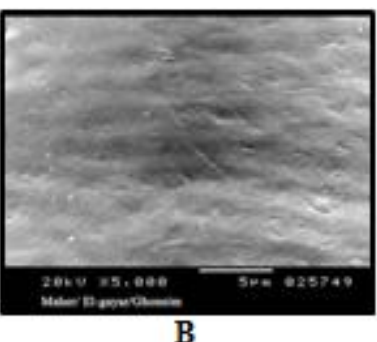

B
Figure 3: SEM micrograph of the sound enamel surface indicating "no alterations".

- SEM micrograph of enamel bleached with $10 \%$ carbamide peroxide only

Bleached group showed alterations on surface smoothness and presented different levels of surface changes. Significant changes of the enamel surface occurred in samples treated with $10 \% \mathrm{CP}$ for 8 hours daily for 14 days. This aspect suggested an increase in the enamel porosity, as compared to unbleached group. (Figure 4) 


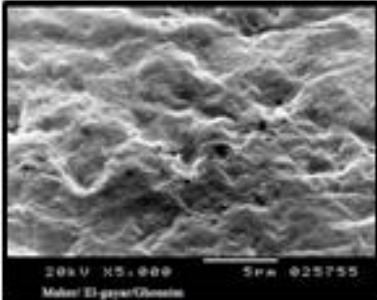

A

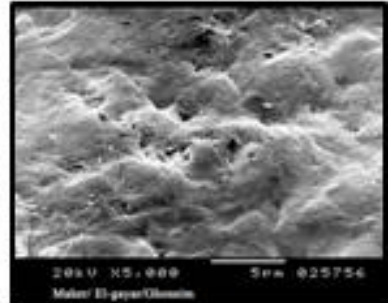

B

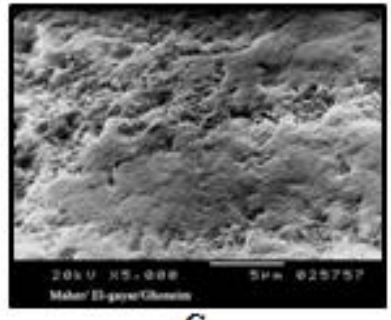

C

Figure 4: SEM micrograph of enamel bleached with $10 \%$ carbamide peroxide only.

- SEM micrograph of enamel bleached with $10 \%$ carbamide peroxide + casein phosphopeptide amorphous calcium phosphate

The SEM images of enamel treated with $10 \%$ carbamide peroxide + casein phosphopeptide amorphous calcium phosphate similar to those of unbleached group, the surface was smooth with slight alterations. (Figure 5)

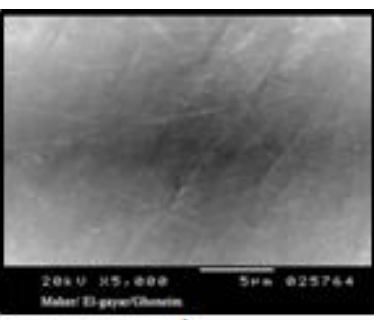

A

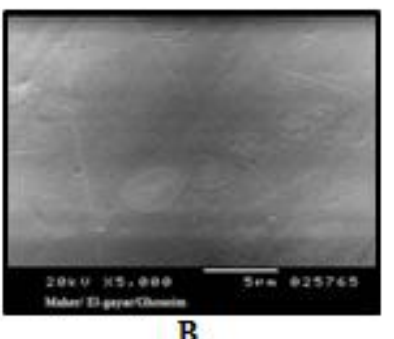

B
Figure 5: SEM micrograph of enamel bleached with $10 \%$ carbamide peroxide + casein phosphopeptide amorphous calcium phosphate

- SEM micrograph of enamel bleached with $15 \%$ carbamide peroxide only

The surface alterations were much more significant than group bleached with $10 \%$ carbamide peroxide. The acidetched enamel had a rough and uneven surface, which indicated alterations of the prismatic structure of the enamel due to selective dissolution of the apatite crystals. Formation of an irregular meshwork and dissolution in central (intraprismatic) or peripheral (interprismatic) part of the prism took place as a result of demineralization. The loss of superficial structure was evident. (Figure 6)

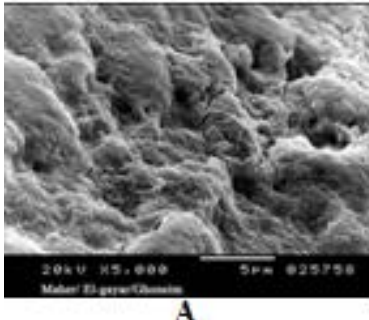

A

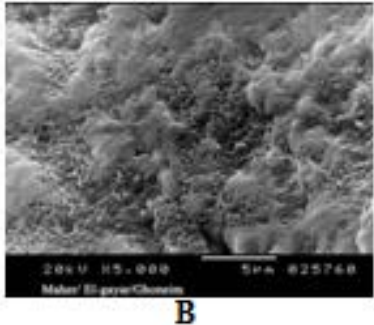

B
Figure 6: SEM micrograph of enamel bleached with $15 \%$ carbamide peroxide only
- SEM micrograph of enamel bleached with $15 \%$ carbamide peroxide + casein phosphopeptide amorphous calcium phosphate

The SEM images of enamel treated with $15 \%$ carbamide peroxide + casein phosphopeptide amorphous calcium phosphate showed mild alterations on surface smoothness and slightly increased porosity. (Figure 7)

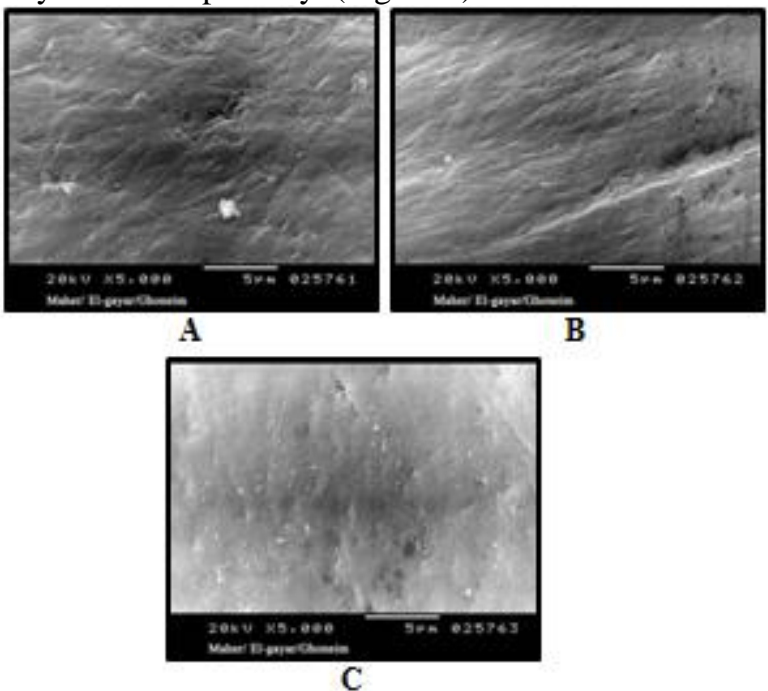

Figure 7: SEM micrograph of enamel bleached with $15 \%$ carbamide peroxide + casein phosphopeptide amorphous calcium phosphate

\section{Discussion}

The tooth color is currently believed to be one of the biggest concerns for patients [17].

The oxide-reduction reaction of the bleaching agent could lead to the dissolution of the organic and inorganic dental matrix until only carbon dioxide and water remain [18]. It has been shown that carbamide peroxide bleaching gels containing fluoride and/or calcium are able to reduce microhardness loss and accelerate microhardness recovery in the posttreatment phase better than nonenhanced gels [19].

Although tooth fragments are frequently used in bleaching studies [20], the entire crown was used in the present investigation, as elsewhere [21]. Using the entire tooth crown is an easier and lower cost method when compared with enamel blocks. Moreover, this method approximates laboratory conditions in the clinical environment, in that bleaching agents are placed on coronal enamel using trays. However, some procedures that do not mirror clinical conditions were included in this study. Enamel was flattened before subjecting the teeth to bleaching, and no brushing of samples was applied during the bleaching procedures in order to be certain that any change on enamel surface was due to the active ingredients of the bleaching gels without external interferences [22].

In the current study, storage in saliva was chosen to simulate the oral environment. Human saliva from different individuals has varying properties, and also the $\mathrm{pH}$ of saliva differs from person to person. Therefore, the artificial saliva was used instead of human saliva in order to standardize the conditions in the study [23].

Volume 5 Issue 6, June 2016 www.ijsr.net 


\section{International Journal of Science and Research (IJSR) \\ ISSN (Online): 2319-7064 \\ Index Copernicus Value (2013): 6.14 | Impact Factor (2015): 6.391}

Bleaching agents with low concentrations of carbamide peroxide $(10 \%)$ result in a change in phosphate, besides the calcium and fluoride content of enamel. Thus, a remineralization system should supply stabilized bioavailable calcium, phosphate, and fluoride ions [24] because all of these minerals may be lost after bleaching. It has been shown that gels containing ACP affected remineralization patterns of predemineralized bovine enamel better than fluoridated (sodium fluoride) bleaching agents [25]. However, the ACP system stabilized by CPP, otherwise known as CPP-ACP, provides a higher reservoir of bioavailable calcium and phosphate ions in comparison with ACP only, leading to an increased remineralization potential [24]. Although a large body of scientific evidence demonstrates that CPP-ACP could promote the remineralization.

A hardness loss could classically be related to mineral content loss resulting from demineralization; therefore, the microhardness test is often applied to evaluate the adverse effects of bleaching agents on enamel [26].

The surface morphology of the studied enamel was observed by scanning electon microscopy (SEM) as the method was presents in most studies evaluating the microstructure of enamel. This method has commonly been used to evaluate the effect of bleaching agents on the surface of dental hard tissues, mainly on enamel [27].

The result of this study showed that the application of CPPACP paste (MI paste) to $10 \%$ and $15 \%$ carbamide peroxide increase the midrohardness using Vicker hardness tester and also the use of this paste was able to prevent negative morphological changes in enamel surface that was observed using scanning electron microscopy.

These results were in agreement with Borges et al [28] as they found the addition of minerals to bleaching gels can potentially reduce the most adverse effects of tooth bleaching, probably without affecting the efficiency of bleaching gels or changing the hardness or morphology of the substrates studied. The addition of CPP-ACP to dental bleaching gels contributes to increased enamel hardness and roughness, and may protect enamel from morphological changes or induce the accumulation of granules suggestive of minerals.

According to the results of the present study that found that bleaching with $16 \%$ carbamide peroxide is more aggressive and affect enamel mineral contents and surface morphology with obviously seen by SEM images and hardness number values. These results are consistent with Soares et al [29] who compare the effect of $16 \%$ carbamide peroxide and 10\% carbamide perodixe on mineralized enamel content and morphology and found that the higher $\mathrm{CP}$ concentrations in the bleaching gel result in higher and faster decrease in dental enamel microhardness.

The results of this study also were in agreement with Borges et al studied the bleaching agents with low concentrations of carbamide peroxide (10\%) might result in a change in phosphate, besides the calcium and fluoride content of enamel [30]. Thus, a remineralization system should supply stabilized bioavailable calcium, phosphate, and fluoride ions because all of these minerals may be lost after bleaching [24].

They found that ACP affected remineralization patterns of predemineralized bovine enamel better than fluoridated (sodium fluoride) bleaching agents. However, the ACP system stabilized by CPP, otherwise known as CPP-ACP, provides a higher reservoir of bioavailable calcium and phosphate ions in comparison with ACP only, leading to an increased remineralization potential [24].

Also Poggio et al,[14] intact enamel exposed to bleaching agents showed porosities, depressions, and superficial alterations at various degrees. The bleached enamel showed in fact slight and moderate irregularities, significantly different from non-treated enamel, which presented a smooth surface morphology. These findings are in agreement with authors who detected the same deleterious effects.

Also Kallepall and Dash [31] who use McInnes bleaching solution which was selected as it recommended for treatment of teeth with fluorosis and it was easy manipulation and less expensive when compared to carbamide peroxide and they found that it decreased the microhardness of enamel and all remineralizing agents used increased the microhardness of enamel. Also a study by Penumatsa et al used $20 \%$ carbamide peroxide and $35 \%$ carbamide peroxide they found that bleaching agents reduced enamel microhardness and the use of CPP-ACP after bleaching can significantly enhance the microhardness of bleached enamel.

De Vasconcelos et al and Borges et al [13] observed increases in the hardness of dental enamel following the use of whitening gel containing CPP-ACP. Statistical analysis revealed significant differences $(p<0.05)$ in hardness values obtained before and after bleaching, leading to the conclusion that this mineral can increase enamel hardness when used with home or in-office bleaching. The increased post-bleaching microhardness for samples bleached using peroxides with CPP-ACP suggests a mineral deposition on enamel. It is likely that this mineral gain was also favored by the synergist effect of fluoride contained in the peroxides with CPPACP on enamel remineralization.

The authors of one study that evaluated morphological changes in enamel via SEM after bleaching with $16 \%$ carbamide peroxide and $7.5 \%$ HP gels with different concentrations of CPP-ACP attributed the accumulation of granules suggestive of minerals on tooth enamel to this mineral. Depressions and irregularities were observed on enamel surfaces in the control group, which was treated with bleaching gel alone. In this case, increased roughness due to CPP-ACP deposition was not considered a negative effect due to the benefits of CPP-ACP on dental tissues. In contrast, another study found that gels containing CPP-ACP resulted in no change to the enamel surface, suggesting that this mineral protected the enamel from potential morphological changes caused by the whitening gel [32].

On the other hand conversely, these results were in contrast with researches done by Abo-Hamar and Etman [33] found that bleaching with $10 \%$ carbamide peroxide $1 \mathrm{~h} /$ day for 14 days or by $9.5 \%$ HP $30 \mathrm{~min} /$ day for 40 days didn't significantly decrease enamel $\mathrm{VH}$ and they explained that by

\section{Volume 5 Issue 6, June 2016}

www.ijsr.net 


\section{International Journal of Science and Research (IJSR) \\ ISSN (Online): 2319-7064}

Index Copernicus Value (2013): 6.14 | Impact Factor (2015): 6.391

it may be due to the balance between the demineralization and remineralization that was performed by artificial saliva.

Also a study by Soares et al [34] who found that although some remineralizing products provided microhardness recovery and positive effect on enamel morphology at $24 \mathrm{~h}$ post-bleaching, non of them were able to maintain microhardness and enamel morphology at 14 days postbleaching.

These finding might be justified by short term contact of remienralizing agents with enamel. So it should be assumed that a single application is not sufficient to supply the sufficient amount of minerals to maintain microhardness and enamel integrity recovery after bleaching so higher number of applications is necessary.

\section{Conclusions}

According to the limitation of this study, the results indicated that:

The use of CPP-ACP paste with $10 \%$ and $15 \%$ carbamide peroxide increased post bleaching enamel microhardness and was effective on repairing enamel surface morphology.

\section{References}

[1] Alkhatib MN, Holt R, Bedi R. Prevalence of selfassessed tooth discolouration in the United Kingdom. J Dent 2004; 32: 561-6.

[2] Faraoni-Romano JJ, Silveira AG, Turssi CP, Serra MC. Bleaching agents with varying concentrations of carbamide and/or hydrogen peroxides: Effects on dental microhardness and roughness. J Esthet Restor Dent 2008; 20: 395-404.

[3] Attin T, Betke H, Schippan F, Wiegand A. Potential of fluoridated carbamide peroxide gels to support post-bleaching enamel re-hardening. J Dent 2007; 35: 755-9.

[4] Attin T, Schmidin PR, Wegehaupt F, Wiegand A. Influence of study design on the impact of bleaching agents on dental enamel microhardness: A review. J Dent 2009; 25: 143-57.

[5] Araujo FO, Baratieri LN, Araujo E. In situ study of in-office bleaching procedures using light sources on human enamel microhardness. Oper Dent 2010; 35: 139-46.

[6] Gladwell J, Simmons D, Wright JT. Remineralization potential of a fluoridated carbamide peroxide whitening gel. J Esthet Restor Dent 2006; 18: 206-12.

[7] Featherstone JD. Remineralization, the natural caries repair process-the need for new approaches. Adv Dent Res 2009; 21: 4-7.

[8] Cochrane NJ, Cai F, Huq NL, Burrow MF, Reynolds EC. New approaches to en-hance demineralization of tooth enamel. J Dent Res 2010; 89: 1187-97.

[9] de Oliveira R, Paes Leme AF, Giannini M. Effect of a carbamide peroxide bleaching gel containing calcium or fluoride on human enamel surface microhardness. Braz Dent J 2005; 16: 103-6.

[10] Burgmaier GM, Schulze IM, Attin T. Fluoride uptake and development of artificial erosions in bleached and fluoridated enamel in vitro. J Oral Rehabil 2002; 29: 799-804

[11] Manton DJ, Bhide R, Hopcraft MS, Reynolds EC. Effect of ozone and Tooth Mousse on the efficacy of peroxide bleaching. Aust Dent J 2008; 53: 128-32.

[12] Efeoglu N, Wood D, Efeoglu C. Microcomputerised tomography evaluation of $10 \%$ carbamide peroxide applied to enamel. J Dent 2005; 33: 561-7.

[13] BCD Borges _ JS Borges _ CD de Melo IVA Pinheiro AJS dos Santos R Braz MAJR Montes. Efficacy of a Novel At-home Bleaching Technique With Carbamide Peroxides Modified by CPP-ACP and Its Effect on the Microhardness of Bleached Enamel. Oper Dent 2011 36: 521-8.

[14] Poggio C, Grasso N, CECI M, Beltrami R, Colombo M, Chiesa M. Ultrastructural Evaluation of Enamel Surface Morphology After Tooth Bleaching Followed by the Application of Protective Pastes. Scanning 2015; 9999.

[15] Dmitrienko A, Hsu JC. Multiple testing in clinical trials. In: Kotz S, Balakrishnan N, Read CB, Vidakovic B (eds). Encyclopedia of Statistical Sciences. $2^{\text {nd }}$ ed. Hoboken (NJ): John Wiley \& Sons, 2006.

[16] Kirkpatrick LA, Feeney BC. A simple guide to IBM SPSS statistics for version 20.0. Student ed. Belmont, Calif: Wadsworth, Cengage Learning, 2013.

[17] Alkhatib MN, Holt R, Bedi R. Prevalence of selfassessed tooth discolouration in the United Kingdom. J Dent 2004; 32: 561-6.

[18] Soldani P, Amaral CM, Rodrigues JA. Microhardness evaluation of in situ vital bleaching and thickening agents on human dental enamel. Int $\mathbf{J}$ Periodontics Restorative Dent 2010; 30: 203-11.

[19] Cavalli V, Rodrigues LK, Paes-Leme AF, Brancalion ML, Arruda MA, Berger SB, et al. Effects of bleaching agents containing fluoride and calcium on human enamel Quintessence Int 2010; 41: e157-e65.

[20] Gomes MN, Francci C, Medeiros IS, Froes-Salgado NR, Riehl E, Marasca JM, et al. Effect of light irradiation on tooth whitening: Enamel microhardness and color change. J Esthet Restor Dent 2009; 21: 387-96.

[21] Borges AB, Yui KC, D’Avila TC, Takahashi CL, Torres $\mathrm{CR}$, Borges $\mathrm{AL}$. Influence of remineralizing gels on bleached enamel microhardness in different time intervals. Oper Dent 2010; 35: 180-6.

[22] Abouassi T, Wolkewitz M, Hahn P. Effect of carbamide peroxide and hydrogen peroxide on enamel surface: An in vitro study. Clin Oral Investig 2011; 15: 673-80.

[23] Singh RD, Ram SM, Shetty O, Chand P, Yadav R. Efficacy of casein phosphopeptide-amorphous calcium phosphate to prevent stain absorption on freshly bleached enamel: An in vitro study. J Conserv Dent 2010; 13: 76-9.

[24] Cochrane NJ, Cai F, Huq NL, Burrow MF, Reynolds EC. New approaches to enhanced remineralization of tooth enamel. J Dent Res 2010; 89 1187-97.

[25] Tschoppe P, Neumann K, Mueller J, Kielbassa AM. Effect of fluoridated bleaching gels on remineralization of predemineralized bovine enamel in vitro. J Dent 2009; 37: 156-62.

[26] Attin T, Schmidin PR, Wegehaupt F, Wiegand A. Influence of study design on the impact of bleaching agents on dental enamel microhardness: a review. J Dent 2009; 25: 143-57.

\section{Volume 5 Issue 6, June 2016} www.ijsr.net 


\section{International Journal of Science and Research (IJSR) \\ ISSN (Online): 2319-7064}

Index Copernicus Value (2013): 6.14 | Impact Factor (2015): 6.391

[27] Auschill TM, Hellwig E, Schmidale S, Sculean A, Arweiler NB. Efficacy, side-effects and patients acceptance of different bleaching techniques (OTC, in-office, at-home). Oper Dent 2005; 30: 156-63.

[28] Borges B, Vale M, Afonso F, Assunção I. Can Enhanced Peroxides Decrease the Side Effects of Tooth Bleaching? A Systematic Review of the Literature. Int J Exper Dent Sci 2014; 3: 84-91

[29] Eimar H, Siciliano R, Abdallah MN, Nader SA, Amin WM, Martinez PP, et al. Hydrogen peroxide whitens teeth by oxidizing the organic structure. J Dent 2012; 40: e25-e33.

[30] Efeoglu N, Wood D, Efeoglu C. Microcomputerised tomography evaluation of $10 \%$ carbamide peroxide applied to enamel. J Dent 2005; 33: 561-7.

[31] Penumatsa NV, Kaminedi RR, Baroudi K, Barakath O. Evaluation of remineralization capacity of casein phosphopeptide-amorphous calcium phosphate on the carbamide peroxide treated enamel. J Pharm Bioallied Sci 2015; 7(Suppl 2): S583-6.

[32] Borges BC, Pinheiro MH, De Sousa Feitosa DA, Correia TC, Braz R, Montes MA, et al. Preliminary study of a novel in-office bleaching therapy modified with a casein phosphopeptide- amorphous calcium phosphate. Microsc Res Tech 2012; 75: 1571-5.

[33] Abo-Hamar SE, Etman WM. Effect of repeated bleaching by low hydrogen peroxide regimens - with and without MI Paste Plus - on enamel hardness and composition. Tanta Dent J 2014; 11: 114-21.

[34] Soares MUSD, Araujo NC, Borges BCD, Sales WD, Sobral APV. Impact of remineralizing agents on enamel microhardness recovery after in-office tooth bleaching therapies. Acta Odontologica Scandinavica 2013; 71: 343-8.

\section{Author Profile}

Hagar Maher Ali, received the B.D.S. In Dental and Oral Surgery from Alexandria University, faculty of Dentistry 2004. During 2004-2016, she practiced in Ministry of Health. Since 2004 till now, she is one of the staff of Alex dental research center. During 2011-2016, she educated for M.S degree in Operative department, Faculty of Dentistry. Alexandria University. 